\title{
Storylines of atmospheric circulation change for European regional climate impact assessment
}

Article

Published Version

Creative Commons: Attribution 4.0 (CC-BY)

Open Access

Zappa, G. and Shepherd, T. G. (2017) Storylines of atmospheric circulation change for European regional climate impact assessment. Journal of Climate, 30 (16). pp. 65616577. ISSN 1520-0442 doi: https://doi.org/10.1175/JCLI-D-160807.1 Available at https://centaur.reading.ac.uk/70531/

It is advisable to refer to the publisher's version if you intend to cite from the work. See Guidance on citing.

To link to this article DOI: http://dx.doi.org/10.1175/JCLI-D-16-0807.1

Publisher: American Meteorological Society

All outputs in CentAUR are protected by Intellectual Property Rights law, including copyright law. Copyright and IPR is retained by the creators or other copyright holders. Terms and conditions for use of this material are defined in the End User Agreement.

www.reading.ac.uk/centaur

\section{CentAUR}


Central Archive at the University of Reading

Reading's research outputs online 


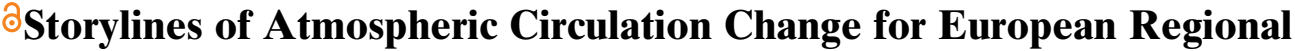 Climate Impact Assessment ${ }^{\mathscr{O}}$
}

\author{
GIUSEPPE ZAPPA AND THEODORE G. SHEPHERD \\ Department of Meteorology, University of Reading, Reading, United Kingdom
}

(Manuscript received 11 November 2016, in final form 26 May 2017)

\begin{abstract}
There is increasing interest in understanding the regional impacts of different global warming targets. However, several regional climate impacts depend on the atmospheric circulation, whose response to climate change remains substantially uncertain and not interpretable in a probabilistic sense in multimodel ensemble projections. To account for these uncertainties, a novel approach where regional climate change is analyzed as a function of carbon emissions conditional on plausible storylines of atmospheric circulation change is here presented and applied to the CMIP5 models' future projections. The different storylines are determined based on the response in three remote drivers of regional circulation: the tropical and polar amplification of global warming and changes in stratospheric vortex strength. As an illustration of this approach, it is shown that the severity of the projected wintertime Mediterranean precipitation decline and central European windiness increase strongly depends on the storyline of circulation change. For a given magnitude of global warming, the highest impact storyline for these aspects of European climate is found for a high tropical amplification and a strengthening of the vortex. The difference in the precipitation and wind responses between the storylines is substantial and equivalent to the contribution from several degrees of global warming. Improving the understanding of the remote driver responses is thus needed to better bound the projected regional impacts in the European sector. The value of these storylines to represent the uncertainty in regional climate projections and to inform the selection of CMIP5 models in regional climate impact studies is discussed.
\end{abstract}

\section{Introduction}

There is increasing interest to evaluate the regional impacts of climate change and to understand how these may vary for different levels of global warming (Hulme 2016). The 2016 Paris agreement posed the ambitious goal of limiting global warming at $1.5^{\circ} \mathrm{C}$ above preindustrial levels, $0.5^{\circ} \mathrm{C}$ less than previous mitigation targets. However, determining the climate impacts avoided from this additional $0.5^{\circ} \mathrm{C}$ of global warming remains challenging. While the future response in some impact-relevant thermodynamic aspects of climate

Denotes content that is immediately available upon publication as open access.

Supplemental information related to this paper is available at the Journals Online website: http://dx.doi.org/10.1175/ JCLI-D-16-0807.s1.

Corresponding author: Giuseppe Zappa,g.zappa@reading.ac.uk might be directly linked to global warming targets (Seneviratne et al. 2016), future changes in regional hydroclimates and storminess are strongly driven by the atmospheric circulation whose response to climate change remains substantially uncertain (Woollings 2010; Shepherd 2014). It is thus necessary to understand, characterize, and communicate this uncertainty to end users in order to fully evaluate the potential impacts of climate change and inform the definition of climate mitigation policies.

Future projections from multimodel ensembles of climate models, such as the Coupled Model Intercomparison Project (CMIP), are used to explore the uncertainty in the response of the climate system to greenhouse gas and aerosol forcing. These projections reveal that individual climate models can show a pattern of atmospheric circulation change that is qualitatively different from the multimodel mean projection (see Figs. 1a-c). However, the multimodel mean cannot be interpreted as the best estimate climate change response, as climate models have shared biases in the representation of Earth's climate and this implies that 
a)

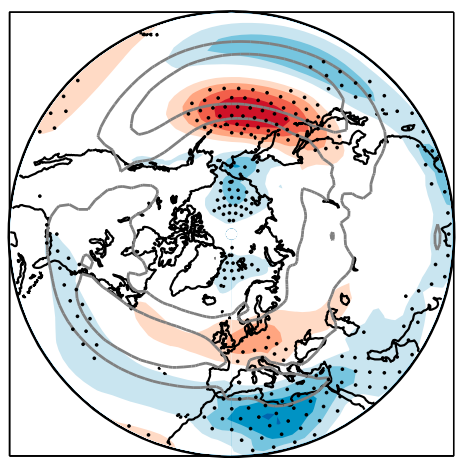

b) $\quad$ CSIRO-mk3.6.0

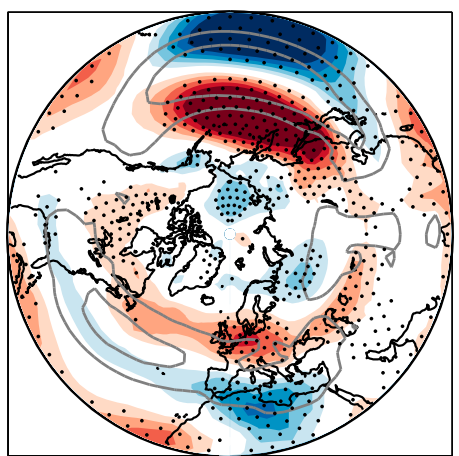

c)

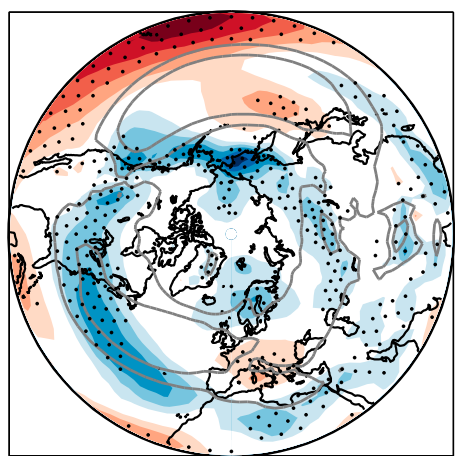

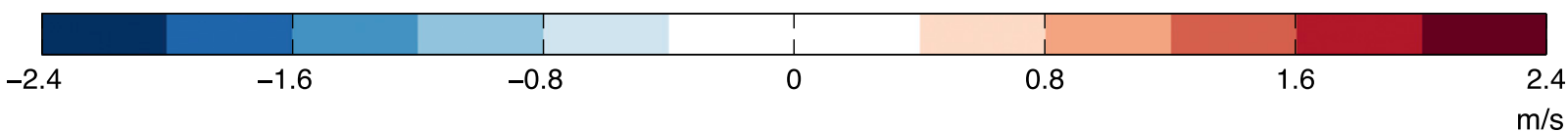

FIG. 1. (a) Cold season [November-April (NDJFMA)] response to climate change in the zonal wind at $850 \mathrm{hPa}$ (U850) according to the CMIP5 multimodel mean (shading). The climate response is evaluated as the difference between the 2070-2100 mean in the RCP8.5 scenario minus the 1960-90 mean in the historical simulations. The gray contours mark the $8 \mathrm{~m} \mathrm{~s}^{-1}$ (inner) and $4 \mathrm{~m} \mathrm{~s}^{-1}$ (outer) multimodel mean zonal wind in the historical simulations. Stippling indicates $90 \%$ intermodel agreement on the direction of change. (b),(c) As in (a), but for the CSIRO Mk3.6.0 and CanESM2 climate model responses averaged over 10 and 5 ensemble members, respectively. Stippling indicates significance at the $5 \%$ level based on the ensemble members' spread. Note how the patterns of circulation change in the individual models can differ from that found in the multimodel mean.

multimodel ensembles cannot be interpreted in a probabilistic sense (Knutti et al. 2010, 2013). Multimodel projections could potentially be refined by identifying how the uncertainty in the future response depends on model biases, but this has only been successfully applied to reduce uncertainty in a few regional climate aspects (Hall and Qu 2006; Bracegirdle and Stephenson 2013; Simpson et al. 2016).

Recognizing the importance of accounting for model diversity in the assessment of regional climate impacts, different international programs have been promoted to apply the same regional climate models and impact models to the output of different CMIP5 GCMs (Giorgi et al. 2009; Warszawski et al. 2014). However, the matrix of possible combinations among the various GCMs, RCMs, and impact models is so large that only some of the combinations are actually explored (Kendon et al. 2010). This further complicates any probabilistic interpretation of the resulting regional impacts, and it poses the question of how to select driving GCMs that are representative of the full range of possible responses (Pierce et al. 2009; McSweeney et al. 2015; McSweeney and Jones 2016).

These limitations in interpreting multimodel ensembles and the large uncertainty in the atmospheric circulation response have motivated some climate services to present climate projections using an alternative storyline-based approach. In the storyline approach, regional impacts are conditioned on the occurrence of particular weather events or on a range of plausible scenarios of atmospheric circulation change (Hazeleger et al. 2015; Meredith et al. 2015; Shepherd 2016a). A pioneering example of the latter is found in the KNMI'14 assessment of climate change impacts in the Netherlands (van den Hurk et al. 2014a). Storylines of higher or lower regional precipitation change, which are shown to depend on the regional atmospheric circulation response, are generated by bootstrapping one model's internal climate variability (Lenderink et al. 2014; van den Hurk et al. 2014b). Two additional storylines are also generated to characterize scenarios of higher or lower regional warming. While these storylines do not represent any specific CMIP5 model simulation, they tend to capture most of the spread in the CMIP5 regional precipitation and temperature projections, thus greatly simplifying the interpretation of the multimodel ensemble. This paper aims to advance the use of storylines in regional climate impact assessment by proposing a novel approach that is self-consistent, informative for users, and physically based on the role of teleconnections in setting circulation anomalies at the regional scale.

In the midlatitudes, atmospheric-related climate impacts are strongly influenced by the behavior of jet streams and storm tracks (Della-Marta and Pinto 2009). Experience from seasonal prediction suggests that regional jet stream anomalies generally arise as part of teleconnections linked to anomalies in other regions. For the Northern Hemisphere $(\mathrm{NH})$ wintertime, three main sources of seasonal predictability are the state of the tropical sea surface temperature (SST), the Arctic sea ice, 
and the stratosphere (Scaife et al. 2014). All these aspects of climate are also characterized by large uncertainty in the CMIP5 future projections (Stroeve et al. 2012; Ma and Xie 2013; Chadwick et al. 2013), and Manzini et al. (2014) showed that they are associated with, and potentially drive, part of the uncertainty in the atmospheric circulation response to climate change in the Northern Hemisphere extratropics. In particular, the warming of tropical SST induces an upper-tropospheric tropical amplification of global warming via changes in the moist adiabatic lapse rate, while sea ice lost contributes to a polar amplification of global warming, thus affecting the meridional atmospheric temperature gradients on which storm tracks grow (Butler et al. 2010; Harvey et al. 2014). We thus hypothesize that while, as in pattern scaling (Mitchell 2003; Tebaldi and Arblaster 2014), global warming sets the overall amplitude of the climate change response, different patterns in the atmospheric circulation response can result from the competing effects of these three remote drivers of midlatitude circulation change: tropical and polar amplification of global warming and changes in the stratospheric vortex strength.

A novel regression framework incorporating these hypotheses has been developed and applied to generate a plausible range of storylines starting from the CMIP5 models' future projections. The framework is general, and each storyline describes the best estimate response conditional on the response of the remote drivers. In this way, the question shifts from asking whether a specific model is believable to asking what storyline of circulation change is most likely to happen. In contrast to the previous approaches, the proposed storylines are global and are physically anchored on the impact that remote drivers and global teleconnections have on the regional climate. Nonetheless, these global storylines can be tailored to inform specific impact-related climate aspects. In particular, we will here describe storylines characterizing a range of plausible scenarios for two impact-related aspects of European climate: cold-season Mediterranean precipitation and central European windiness.

\section{Methods}

\section{a. CMIP5 models and data}

32 CMIP5 models (see Table 1) have been analyzed in this work. These are the models for which the needed data were available apart from FGOALS-g2 and FIO-ESM, which have been excluded as outlying. FGOALS-g2 has a much larger bias in the position of the North Atlantic jet and storm track than any other CMIP5 model (Zappa et al. 2013), and this could directly affect its regional circulation response. FIO-ESM is the only model with no polar amplification of global warming, which is possibly due to a severe reduction in the strength of the Atlantic meridional overturning circulation (Collins et al. 2013). However, the identified storylines of atmospheric circulation change are not qualitatively affected by the inclusion of these models. The model data have been interpolated to a common T42 spatial grid using conservative remapping for precipitation and bilinear interpolation for all the other variables.

The end-of-century climate change response is defined as the 2070-2100 30-yr mean climate in the RCP8.5 emissions scenario minus the 1960-90 climate in the historical simulations (Taylor et al. 2012), with the cold season [November-April (NDJFMA)] averages starting in November 2069 and November 1959, respectively. All the available ensemble members have been used to estimate the climate change response of each model so as to reduce the uncertainty due to internal climate variability.

\section{b. Definitions of remote drivers}

The remote drivers of climate are defined by scaling by global warming $(\Delta T)$ each of the three global indices introduced in Manzini et al. (2014):

- polar warming $\left(\Delta T_{\text {polar }}\right)$ : temperature change at $850 \mathrm{hPa}$ averaged between $60^{\circ}$ and $90^{\circ} \mathrm{N}$,

- tropical warming $\left(\Delta T_{\text {trop }}\right)$ : temperature change at $250 \mathrm{hPa}$ averaged between $30^{\circ} \mathrm{S}$ and $30^{\circ} \mathrm{N}$, and

- stratospheric vortex strength $\left(\Delta U_{\text {strat }}\right)$ : zonal mean zonal-wind change at $20 \mathrm{hPa}$ averaged between $70^{\circ}$ and $80^{\circ} \mathrm{N}$

Unlike Manzini et al. (2014), the indices are evaluated for the cold season (NDJFMA) rather than for the meteorological winter season (DJF), and some indices are evaluated at a slightly different vertical level (250 vs $150 \mathrm{hPa}$ for the tropical amplification and $20 \mathrm{vs} 10 \mathrm{hPa}$ for the vortex response). Most importantly, as mentioned above, the three indices are all scaled by the annual-mean near-surface atmospheric global warming $(\Delta T)$, which is not done in Manzini et al. (2014). All spatial averages have been area weighted.

The unscaled response of the remote drivers to climate change is summarized in Figs. 2a and 2b. The CMIP5 climate models show amplified warming in the tropical upper troposphere and in the Arctic, but with uncertain amplification rate, while the stratospheric vortex can either weaken or strengthen. This latter result is similar to what is found in Manzini et al. (2014), where 66\% of the models show a weakening of the stratospheric vortex in DJF.

\section{c. Regression framework}

By adopting the pattern scaling assumption, the endof-century climate change response $\left(\Delta C_{x m}\right)$ in a field $C$ at location $x$, in model $m$ is written as 
TABLE 1. List of CMIP5 models considered in the study. For each model, the number of ensemble members for which monthly and daily data are available are separately indicated for the historical (HIST) and RCP8.5 experiments. The dash indicates that the data are not available. (Expansions of acronyms are available online at http://www.ametsoc.org/PubsAcronymList.)

\begin{tabular}{|c|c|c|c|c|c|c|}
\hline & \multicolumn{2}{|r|}{ Basic information } & \multicolumn{2}{|c|}{ No. runs monthly } & \multicolumn{2}{|c|}{ No. runs daily } \\
\hline & Model name & Institution & HIST & RCP8.5 & HIST & RCP8.5 \\
\hline 1 & ACCESS1.0 & CSIRO-BoM, Australia & 1 & 1 & 1 & 1 \\
\hline 2 & ACCESS1.3 & & 3 & 1 & 1 & 1 \\
\hline 3 & BCC_CSM1.1 & BCC, China & 3 & 1 & - & - \\
\hline 4 & BCC_CSM1.1(m) & & 3 & 1 & 1 & 1 \\
\hline 5 & BNU-ESM & Beijing Normal University, China & 1 & 1 & 1 & 1 \\
\hline 6 & CCSM4 & NCAR, United States & 6 & 6 & 1 & 1 \\
\hline 7 & CESM1(CAM5) & NSF-DOE-NCAR, United States & 3 & 3 & - & - \\
\hline 8 & CESM1(WACCM) & & 4 & 3 & - & - \\
\hline 9 & $\mathrm{CMCC}-\mathrm{CM}$ & CMCC, Italy & 1 & 1 & 1 & 1 \\
\hline 10 & CMCC-CMS & & 1 & 1 & 1 & 1 \\
\hline 11 & CNRM-CM5 & $\begin{array}{l}\text { Centre National de Recherches Météorologiques, } \\
\text { France }\end{array}$ & 5 & 4 & 1 & 1 \\
\hline 12 & CSIRO Mk3.6.0 & CSIRO, Australia & 10 & 10 & 1 & 1 \\
\hline 13 & CanESM2 & CCCma, Canada & 5 & 5 & 5 & 5 \\
\hline 14 & EC-EARTH & European consortium, Europe & 5 & 3 & 3 & 3 \\
\hline 15 & GFDL CM3 & GFDL, United States & 5 & 1 & 3 & 1 \\
\hline 16 & GFDL-ESM2G & & 1 & 1 & 1 & 1 \\
\hline 17 & GFDL-ESM2M & & 1 & 1 & 1 & 1 \\
\hline 18 & GISS-E2-H & NASA GISS, United States & 5 & 2 & - & - \\
\hline 19 & GISS-E2-R & & 6 & 2 & - & - \\
\hline 20 & HadGEM2-ES & Met Office Hadley Centre, United Kingdom & 4 & 4 & - & - \\
\hline 21 & HadGEM2-CC & & 3 & 3 & 1 & 1 \\
\hline 22 & INM-CM4 & Institute of Numerical Mathematics, Russia & 1 & 1 & 1 & 1 \\
\hline 23 & IPSL-CM5A-LR & IPSL, France & 5 & 4 & 6 & 3 \\
\hline 24 & IPSL-CM5A-MR & & 3 & 1 & 3 & 1 \\
\hline 25 & IPSL-CM5B-LR & & 1 & 1 & 1 & 1 \\
\hline 26 & MIROC-ESM & $\begin{array}{l}\text { JAMSTEC, Atmosphere and Ocean Research Institute } \\
\text { (AORI) (The University of Tokyo), and National } \\
\text { Institute for Environmental Studies (NIES), Japan }\end{array}$ & 3 & 1 & 3 & 1 \\
\hline 27 & MIROC-ESM-CHEM & & 1 & 1 & 1 & 1 \\
\hline 28 & MIROC5 & $\begin{array}{l}\text { AORI (The University of Tokyo), NIES, and } \\
\text { JAMSTEC, Japan }\end{array}$ & 5 & 3 & 5 & 3 \\
\hline 29 & MPI-ESM-LR & Max Planck Institute for Meteorology, Germany & 3 & 3 & 3 & 3 \\
\hline 30 & MPI-ESM-MR & & 3 & 1 & 3 & 1 \\
\hline 31 & MRI-CGCM3 & Meteorological Research Institute, Japan & 3 & 1 & 1 & 1 \\
\hline 32 & NorESM1-M & Norwegian Climate Centre, Norway & 3 & 1 & 3 & 1 \\
\hline
\end{tabular}

$$
\Delta C_{x m}=\Delta T_{m} P_{x m},
$$

where $\Delta T_{m}$ is the global warming index and $P_{x m}$ is the pattern in the climate response. The pattern of the climate response $P_{x m}$ is then expressed as a linear combination of the response of the three remote drivers scaled by global warming:

$$
\begin{aligned}
P_{x m}= & a_{x}+b_{x}\left(\frac{\Delta T_{\text {polar }}}{\Delta T}\right)_{m}^{\prime}+c_{x}\left(\frac{\Delta T_{\text {trop }}}{\Delta T}\right)_{m}^{\prime} \\
& +d_{x}\left(\frac{\Delta U_{\text {strat }}}{\Delta T}\right)_{m}^{\prime}+e_{x m},
\end{aligned}
$$

where the vertical dash ' indicates the standardized anomaly relative to the multimodel mean. Also, $a_{x}$ gives the mean expected response for no anomaly in the response of the drivers relative to the multimodel mean, while $b_{x}, c_{x}$, and $d_{x}$ give the sensitivity of the regional response to anomalies in the remote driver responses; $e_{x m}$ represents residual variations not captured by the linear expansion. Equation (1) can be then divided by $\Delta T_{m}$ to obtain

$$
\begin{aligned}
\frac{\Delta C_{x m}}{\Delta T_{m}}= & a_{x}+b_{x}\left(\frac{\Delta T_{\text {polar }}}{\Delta T}\right)_{m}^{\prime}+c_{x}\left(\frac{\Delta T_{\text {trop }}}{\Delta T}\right)_{m}^{\prime} \\
& +d_{x}\left(\frac{\Delta U_{\text {strat }}}{\Delta T}\right)_{m}^{\prime}+e_{x m} .
\end{aligned}
$$

The estimates of the coefficients (denoted as $\hat{a}_{x}, \hat{b}_{x}, \hat{c}_{x}$, and $\hat{d}_{x}$ ) are determined by fitting the framework to the CMIP5 model output using ordinary multiple linear regression. The approach assumes that the residuals $e_{x m}$ are 
a)

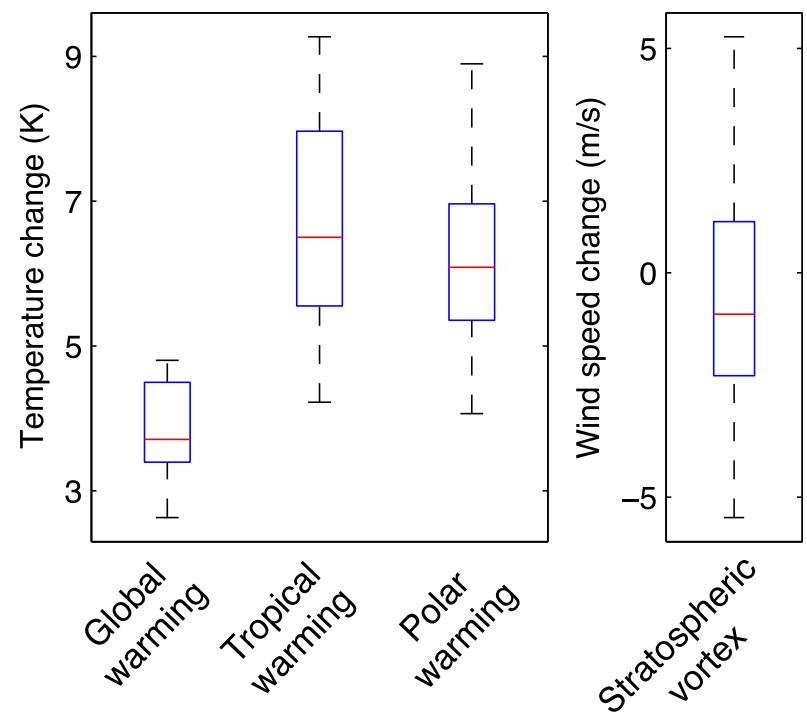

FIG. 2. Spread among the CMIP5 models' climate change responses (2070-2100 minus 1960-90) under the RCP8.5 scenario: (a) global near-surface warming (global warming, $\Delta T$ ), $250-\mathrm{hPa}$ warming over $30^{\circ} \mathrm{S}-30^{\circ} \mathrm{N}$ (tropical warming, $\Delta T_{\text {trop }}$ ), $850-\mathrm{hPa}$ warming over $60^{\circ}-90^{\circ} \mathrm{N}$ (polar warming, $\Delta T_{\text {polar }}$ ) and (b) $20-\mathrm{hPa}$ zonal wind change over $70^{\circ}-80^{\circ} \mathrm{N}$ (stratospheric vortex change, $\left.\Delta U_{\text {strat }}\right)$. Global warming $(\Delta T)$ is evaluated for the annual mean, while the other quantities are evaluated for the cold season. The box plots show the multimodel median (red line), the interquartile range (box), and the full spread (whiskers).

independent and identically distributed, but this is unlikely to be the case when analyzing models from the CMIP5 archive (Knutti et al. 2013). This caveat will be taken into consideration when discussing the results in section 3. The presence of any influence from outlying models is further tested in the online supplemental material.

The key novelty of the framework is that both the atmospheric circulation and the remote driver responses are scaled by the global warming projected by each model. This is important, as it allows us to separate the uncertainty due to global warming from the uncertainty in the pattern of the atmospheric circulation response, and it is justified, as global warming is the ultimate source of climate change. Indeed, scaling by global warming is needed to have uncorrelated tropical and polar warming responses across the CMIP5 model projections (see Table 2). We can thus assume that the responses of the different drivers tend to be affected by independent sources of uncertainty.

Equation (3) implies that different atmospheric circulation patterns can be found depending on the response of the remote drivers. This is used to define a range of plausible storylines, where each storyline is determined
TABLE 2. Pearson correlation coefficient between the driver responses of the CMIP5 models under the RCP8.5 scenario before and after scaling each model driver response by global warming. Bold font indicates statistical significance at the 5\% level (only applied to the cross-correlations).

\begin{tabular}{cccr}
\hline \hline & Polar & Trop & Strat \\
\hline & Before scaling by global warming & \\
Polar & 1.0 & & \\
Trop & $\mathbf{0 . 7}$ & 1.0 & \\
Strat & -0.02 & -0.1 & 1.0 \\
& After scaling by global warming & \\
Polar & 1.0 & & \\
Trop & 0.04 & 1.0 & \\
Strat & -0.06 & -0.2 & 1.0 \\
\hline
\end{tabular}

by the anomaly, or combination of anomalies, in the remote driver responses (e.g., a stronger than average tropical amplification with a weakening of the stratospheric vortex). The validity of the underlying linearity assumption has been verified and it is discussed in the supplemental material. Furthermore, we have also verified the robustness of the results to the presence of outlying data, and verified that the identified signals are not affected by overfitting or dominated by associations arising within the internal climate variability (see the supplemental material).

\section{Atmospheric circulation sensitivity to the remote drivers}

Using the regression framework we first characterize the dependence of the regional atmospheric circulation on the response of the remote drivers. As a simple measure of atmospheric circulation, we examine the zonal component of the time-mean wind at $850 \mathrm{hPa}$ (U850), which is informative of the jet stream position and, indirectly, of the storm-track activity (Woollings et al. 2012). The CMIP5 multimodel mean projection in the $\mathrm{NH}$ cold season indicates a poleward shift of the jet entrance in the North Pacific, an easterly response in North Africa, and a westerly response in central Europe (Fig. 1a). This implies an anticyclonic circulation response in the Mediterranean region, where precipitation is consistently projected to decrease (Seager et al. 2014; Zappa et al. 2015b).

The regression framework identifies strikingly different atmospheric circulation sensitivities to the remote driver responses (Fig. 3). First, the uncertainty in the amplitude of polar amplification is related to U850 wind anomalies at high latitudes, particularly in Europe and Asia (Fig. 3a). While there is as yet no consensus on the atmospheric circulation response to polar amplification (Vihma 2014; Shepherd 2016b), the identified weakening of the westerlies over parts of Siberia and Europe is very similar to what was found in recent numerical experiments where only the Arctic sea ice extent is 


\section{a) Polar amplification}

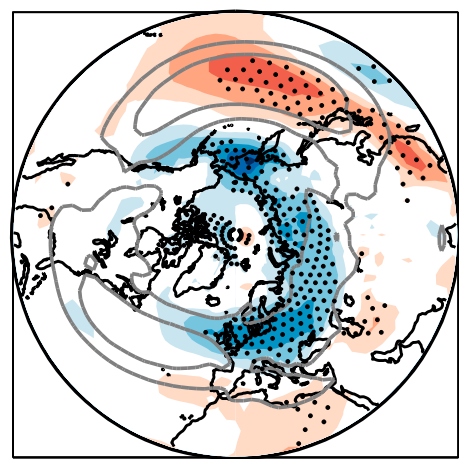

\section{b) Tropical amplification}

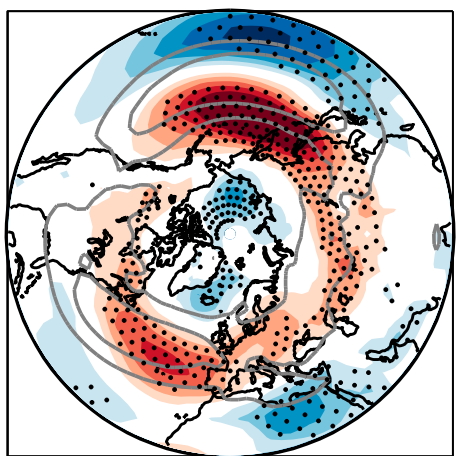

c) Stratospheric vortex

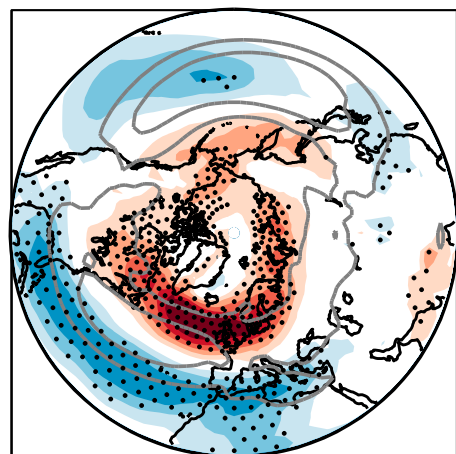

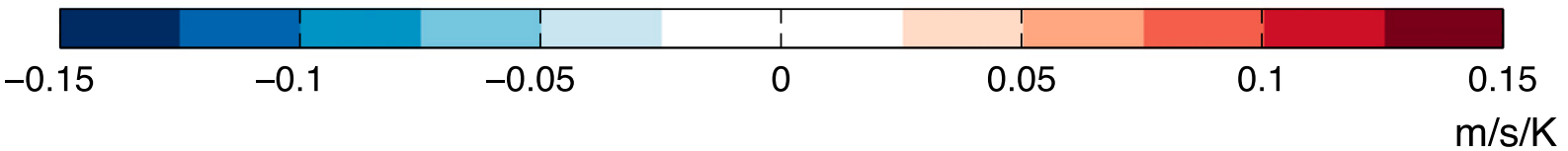

FIG. 3. Sensitivities of the atmospheric circulation response associated with the uncertainties in the remote driver responses. (a) Cold season U850 wind response scaled by global warming $\left(\mathrm{m} \mathrm{s}^{-1} \mathrm{~K}^{-1}\right)$ associated with a one sigma positive anomaly in the polar amplification $\left(\Delta T_{\text {polar }} / \Delta T\right)$ in the CMIP5 intermodel spread. The gray contours mark the $8 \mathrm{~m} \mathrm{~s}^{-1}$ (inner) and $4 \mathrm{~m} \mathrm{~s}^{-1}$ (outer) 850 -hPa zonal wind in the multimodel mean of the historical simulations. Stippling indicates areas with significant regression coefficients at the 5\% level. (b), (c) As in (a), but for the uncertainty associated with a one sigma positive anomaly in the tropical amplification $\left(\Delta T_{\text {trop }} / \Delta T\right)$ and in the scaled change in stratospheric vortex strength $\left(\Delta U_{\text {strat }} / \Delta T\right)$, respectively.

reduced (Sun et al. 2015; Deser et al. 2016). Second, a higher tropical amplification tends to enhance the poleward shift of the North Pacific jet (Fig. 3b), which is a typical behavior in response to tropical warming (Butler et al. 2010). The response to tropical amplification in the North Atlantic sector is instead characterized by a tripolar pattern with an easterly response in North Africa and the Greenland Sea, and a westerly response in the midlatitudes. A climate model experiment where tropical amplification is controlled by increasing the tropical SSTs shows anticyclonic circulation and reduced precipitation in the Mediterranean region (see Figs. 8 and 9 in Hoerling et al. 2012), which is qualitatively consistent with an easterly wind response in North Africa and a westerly response in central Europe. Finally, the uncertainty in the response of the stratospheric vortex is almost exclusively linked to the North Atlantic region (Fig. 3c). In particular, a strengthened stratospheric vortex is associated with a zonal wind anomaly that closely resembles the positive phase of the North Atlantic Oscillation (see Fig. 4c in Ambaum et al. 2001). This is also the tropospheric circulation pattern that follows anomalies in the strength of the stratospheric vortex in the intraseasonal variability (Hitchcock and Simpson 2014). The identified zonal wind patterns are also broadly consistent with the surface pressure signals presented in Fig. 5 of Manzini et al. (2014), where the sign of the stratospheric response is reversed compared to here.
Caution is needed when interpreting correlations across features of multimodel ensembles as, because of the presence of shared model code and biases, climate models are not really independent (Knutti et al. 2013). Correlation does not prove causality and spurious correlations can arise when model dependence is not taken into account (Caldwell et al. 2014). Nonetheless, we find that the statistical relationships identified by the regression framework are qualitatively consistent with separate experimental and observational evidence of how these components of the climate system interact, which gives credence to interpreting them in a physical way.

Locally, up to $50 \%-60 \%$ of the variance in the multimodel spread of the U850 response can be related to the combined effect of the remote drivers and global warming (see Fig. 4). The amount of explained variance reflects the expectation that several other factors, not included as predictor variables in the regression framework, are also likely to influence the regional atmospheric circulation change (e.g., circulation biases, local SST or sea ice anomalies, internal climate variability).

\section{Storylines to assess Mediterranean precipitation change}

We now combine the mean U850 response projected by the CMIP5 models (Fig. 1a) with the above sensitivities to the remote drivers (Figs. $3 \mathrm{a}-\mathrm{c}$ ) to generate a 


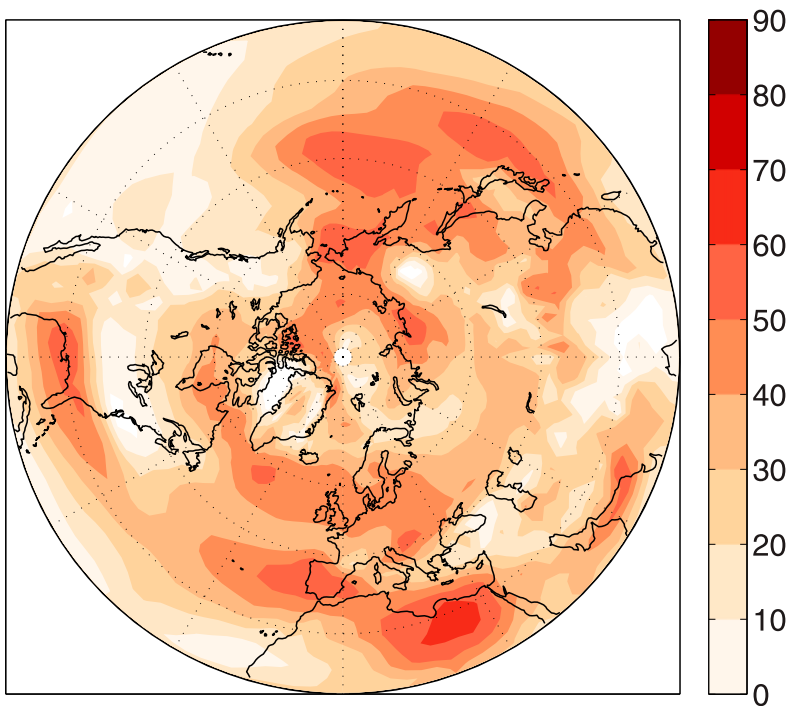

FIG. 4. Fraction of variance ( $R^{2}$ coefficient) of the CMIP5 intermodel spread in the cold season U850 response that can be related to the remote drivers and global warming uncertainty using the regression framework.

range of plausible storylines of circulation change. The storylines inform the expected circulation response per degree of global warming conditional on the response of the remote drivers and they can be tailored to target specific impact-related aspects of climate.

As a first example, we focus on storylines to interpret the cold season Mediterranean precipitation change, whose projected decline can potentially have large socioeconomic impacts (Kelley et al. 2015). Mediterranean precipitation strongly depends on U850 wind anomalies in North Africa (Zappa et al. 2015b), which we find to be mainly linked to uncertainties in tropical amplification and in the stratospheric vortex response (Fig. 3). This is confirmed by directly fitting the regression framework to the CMIP5 precipitation projections (Figs. 5a-c), with the only exception that polar amplification tends to be also associated with precipitation in eastern Turkey.

Four storylines of Euro-Atlantic circulation for Mediterranean impact assessment have been thus created, with each storyline being characterized by a combination of strong or weak tropical amplification and stratospheric vortex responses compared to the multimodel mean. The anomalies in the two driver responses are selected to have equal standardized amplitudes and, to generate plausible but extreme storylines, they are chosen to lie on the $80 \%$ confidence region of the joint distribution (see red dots in Fig. 6). From Eq. (3), the scaled climate responses associated with these four storylines are thus evaluated as

$$
\begin{aligned}
\frac{\Delta C_{x}}{\Delta T} & =\hat{a}_{x} \pm \hat{c}_{x} t \pm \hat{d}_{x} t, \quad \text { and } \\
t & =\sqrt{\chi^{2}(0.8 ; 2) / 2} \sim 1.26,
\end{aligned}
$$

where $\chi^{2}(p ; k)$ is the quantile function of the chi-squared distribution with $k$ degrees of freedom evaluated at probability $p$.

The estimated U850 responses in the four storylines are presented in Fig. 7. A high tropical amplification of global warming $\left(\sim+2 \mathrm{~K} \mathrm{~K}^{-1}\right)$ together with a strengthening of the stratospheric vortex $\left(\sim+0.6 \mathrm{~m} \mathrm{~s}^{-1} \mathrm{~K}^{-1}\right)$ is associated with a poleward shift of the North Atlantic jet, a strengthening of the westerlies in central Europe, and an easterly wind response in North Africa (Fig. 7b). In contrast, the expected U850 response for a model in the opposite storyline (Fig. 7d), that is, with low tropical amplification $\left(\sim+1.5 \mathrm{~K} \mathrm{~K}^{-1}\right)$ and a weakening of the stratospheric vortex $\left(\sim-1.0 \mathrm{~m} \mathrm{~s}^{-1} \mathrm{~K}^{-1}\right)$, is characterized by a weak Euro-Atlantic circulation response with no poleward shift of the jet in the Atlantic. The remaining two storylines describe U850 responses of intermediate amplitude and highlight how a poleward and/or slight southward shift of the North Atlantic jet in the east a) Polar amplification

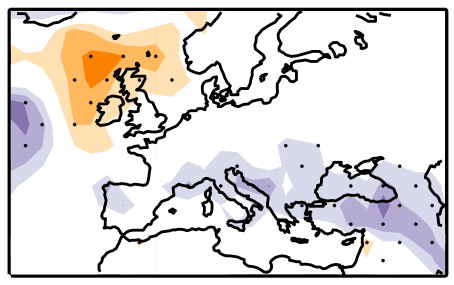

b) Tropical amplification

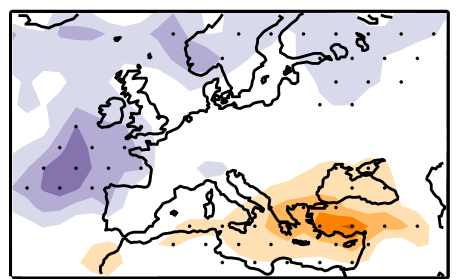

c) Stratospheric vortex

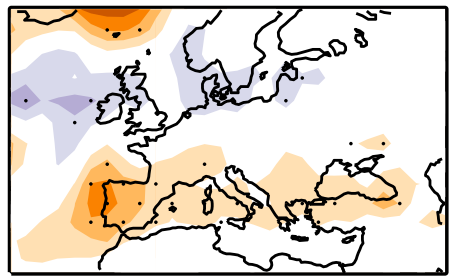

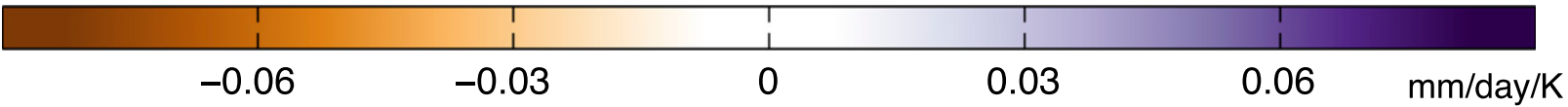

FIG. 5. As in Fig. 3, but for the sensitivity of the European precipitation response associated with the uncertainty in the remote driver responses. 


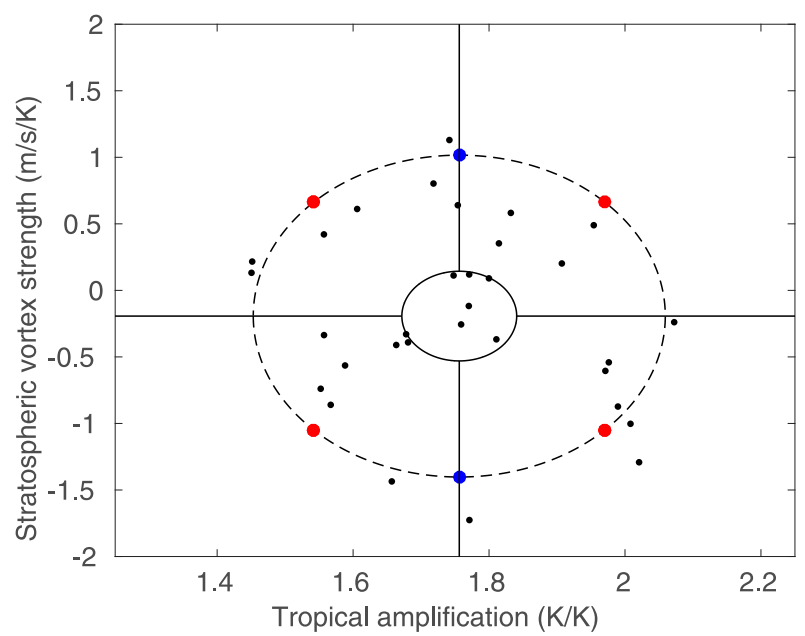

FIG. 6. Individual CMIP5 model responses in the stratospheric vortex strength scaled by global warming against the tropical amplification (black dots). The red dots indicate the selected four storylines that combine anomalies in the tropical amplification and stratospheric vortex responses. The blue dots indicate the two selected storylines based on anomalies in the stratospheric vortex response only. The dashed ellipse shows the $80 \%$ confidence region obtained by fitting a bivariate normal distribution to the model responses. The quadrants delimited by the inner ellipse and by the four straight lines define the regions used to group the models according to the four storylines as described by Eq. (7).

Atlantic are both possible for different combinations of the tropical amplification and stratospheric vortex responses (Figs. 7a,e). In other words, the slight poleward shift of the North Atlantic jet found in the multimodel mean (Fig. 7c) hides a range of possible behaviors that can be linked to the response of the remote drivers.

The identified circulation responses have different implications for Mediterranean precipitation (Fig. 8). The two storylines that include a stronger stratospheric vortex have a larger than average precipitation reduction over Iberia (Figs. 8a,b), which is linked to the tendency of the North Atlantic jet to shift poleward in these storylines (Figs. 7a,b). In contrast, the two storylines that include a high tropical amplification have a larger than average precipitation reduction in the eastern Mediterranean (Figs. 8b,e), which is linked to a more localized anticyclonic circulation centered on the Mediterranean region. This also highlights how the precipitation reduction in the eastern and western Mediterranean regions could potentially have very different amplitudes (cf. Figs. 8a and 8e), something that cannot be inferred by solely inspecting the multimodel mean (Fig. 8c). Overall, each storyline describes a different Mediterranean regional impact scenario due to precipitation change. Higher impacts are expected in the high tropical amplificationstrong vortex storyline, where the precipitation change is about twice as large as in the multimodel mean (Fig. 8c), while lower impacts are expected in the low tropical amplification-weak vortex storyline.

\section{Global warming targets and Mediterranean precipitation change}

Global warming depends on the amount of emitted $\mathrm{CO}_{2}$ and constitutes an additional source of uncertainty on the circulation change and on its subsequent regional impacts. Using the regression framework we can evaluate the role of global warming, which is included as a multiplicative factor, and compare it to the storyline uncertainty. Starting from Eq. (4), the regional climate response is thus written as

$$
\Delta C_{x}=\Delta T\left[\hat{a}_{x}+t_{s}\left(\hat{c}_{x}+\hat{d}_{x}\right)\right],
$$

where $t_{s}$ is a storyline index that represents the standardized anomaly in both the tropical amplification and the stratospheric responses. The low-impact (low tropical amplification-weak vortex) storyline is obtained for $t_{s}=-1.26$, while the high-impact (high tropical amplification-strong vortex) storyline is obtained for $t_{s}=1.26$.

Figure 9a presents the expected area-averaged Mediterranean precipitation reduction as a function of global warming $\Delta T$ and of the storyline index $t_{s}$. The figure highlights how the allowable global warming to avoid exceeding any given threshold in Mediterranean precipitation reduction can strongly depend on the storyline of climate change. For instance, we can consider a threshold related to the time of emergence of the precipitation response $\left(0.08 \mathrm{~mm} \mathrm{day}^{-1}\right.$; light blue line), which indicates the first time when the amplitude of the forced response becomes larger than the trends induced by internal climate variability (Zappa et al. 2015a). For this threshold, the multimodel mean shows an allowable global warming of about $1.3 \mathrm{~K}$ relative to the 1960-90 climate. However, less than $1 \mathrm{~K}$ is allowed according to the high-impact storyline, while more than $3 \mathrm{~K}$ could be allowed in the low-impact storyline. Another important threshold ( $\sim 0.19 \mathrm{~mm} \mathrm{day}^{-1}$; dark blue line) corresponds to one standard deviation in the interannual variability of Mediterranean precipitation (Hawkins and Sutton 2012), that is, a fairly large change that is likely to require adaptation measures. The allowable $\mathrm{CO}_{2}$ emissions and global warming to avoid passing this higher threshold also strongly depend on the storyline of climate change.

To assess the robustness of these findings, we identify the individual climate models that tend to follow the higher- and lower-impact storylines. In particular, models are grouped within each storyline based on their 
a) low tropical amp + strong vortex

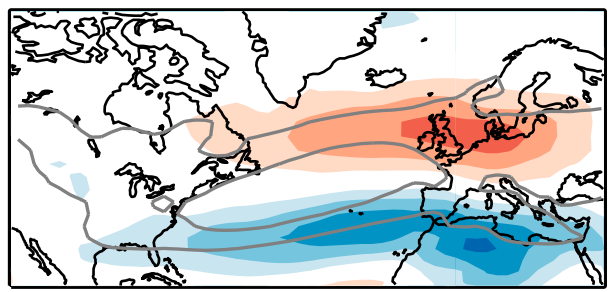

b) high tropical amp + strong vortex

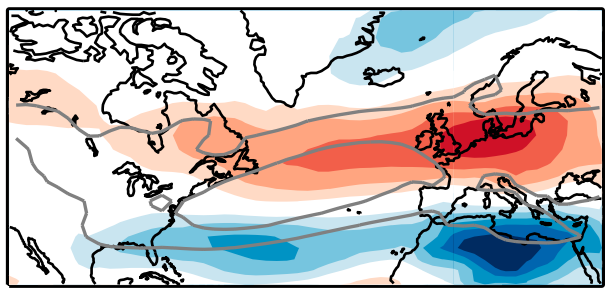

c) multi-model mean

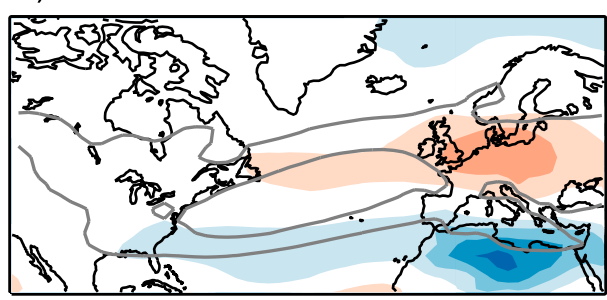

d) low tropical amp + weak vortex

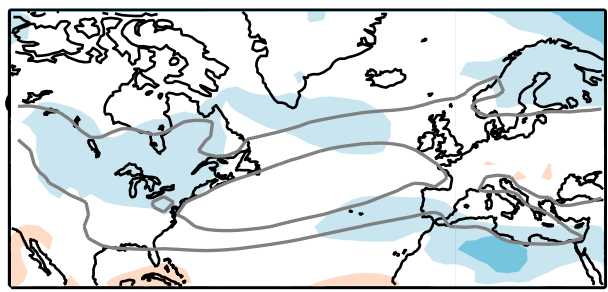

$-0.6$

$-0.4$

$-0.2$
$0.4 \mathrm{~m} / \mathrm{s} / \mathrm{K} 0.6$

e) high tropical amp + weak vortex

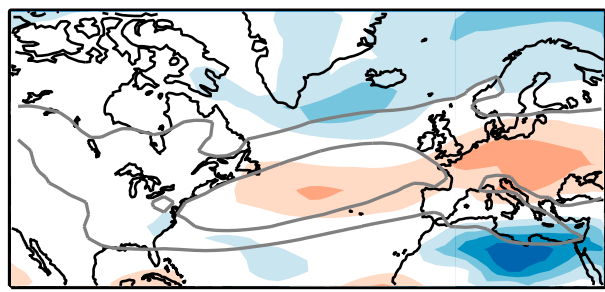

0.2

FIG. 7. Cold season U850 response per degree of global warming $\left(\mathrm{m} \mathrm{s}^{-1} \mathrm{~K}^{-1}\right)$ according to (a),(b),(d),(e) four plausible storylines of climate change that are conditioned on the tropical amplification and stratospheric vortex responses. The storylines have been selected to be of particular relevance for Mediterranean precipitation change. The storylines in (a) and (b) are characterized by a stronger stratospheric vortex, while those in (d) and (e) have a weaker vortex; also, the storylines in (b) and (e) are characterized by higher tropical amplification of global warming, while those in (a) and (d) have lower tropical amplification. (c) The multimodel mean response scaled by global warming. The corresponding driver responses in each storyline are indicated by the four red dots in Fig. 6. The gray contours mark the $8 \mathrm{~m} \mathrm{~s}^{-1}$ (inner) and $4 \mathrm{~m} \mathrm{~s}^{-1}$ (outer) 850 -hPa zonal wind values in the multimodel mean of the historical simulations.

remote driver responses provided that the combined standardized anomaly in the driver responses is greater than 0.5:

$$
\sqrt{\left[\left(\frac{\Delta T_{\text {trop }}}{\Delta T}\right)_{m}^{\prime}\right]^{2}+\left[\left(\frac{\Delta U_{\text {strat }}}{\Delta T}\right)_{m}^{\prime}\right]^{2}}>0.5 .
$$

In other words, the models within each storyline are those delimited by the four quadrants of Fig. 6 with the exclusion of those in the inner ellipse.

Figure $9 \mathrm{~b}$ shows that none of the models in the lowimpact storyline (orange lines and shading) have an areaaveraged Mediterranean precipitation reduction larger than the time of emergence threshold $\left(\sim 0.08 \mathrm{~mm} \mathrm{day}^{-1}\right)$ before reaching $1.5 \mathrm{~K}$ of global warming relative to the 1960-90 mean. In contrast, all the models that tend to have a strengthening of the vortex and a relatively high tropical amplification (high-impact storyline; blue lines and shading) have already reached this threshold before $1.5 \mathrm{~K}$ of global warming. Understanding whether the real world might evolve toward the lower- or higher-impact storyline is a necessary step to evaluate the implications of different global warming targets for Mediterranean precipitation change.

\section{Storylines to assess central European windiness change}

As a second example, we examine the projected changes in windiness in central Europe. Central Europe is already highly vulnerable to windstorm damage from North Atlantic extratropical cyclones (Schwierz et al. 2010; Swiss Re 2010) and therefore susceptible to future changes in the 
a) low tropical amp + strong vortex

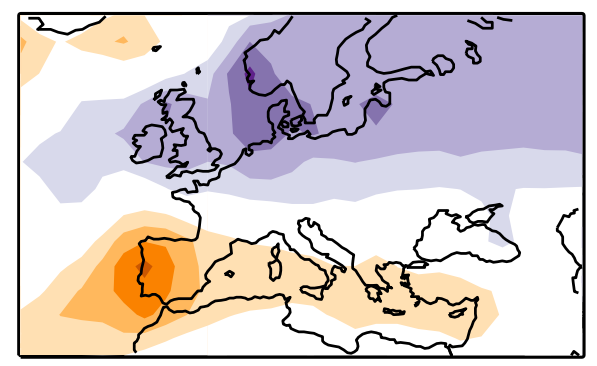

b) high tropical amp + strong vortex

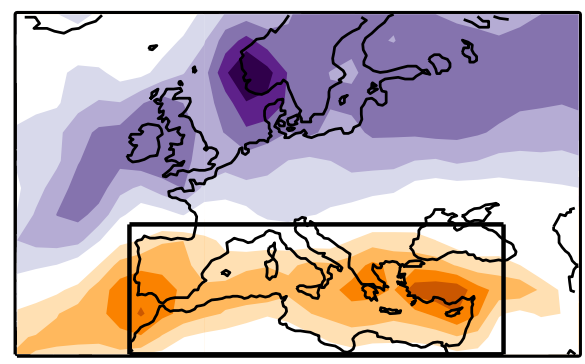

c) multi-model mean

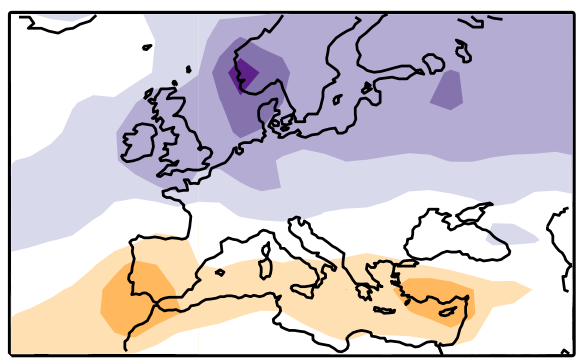

d) low tropical amp + weak vortex

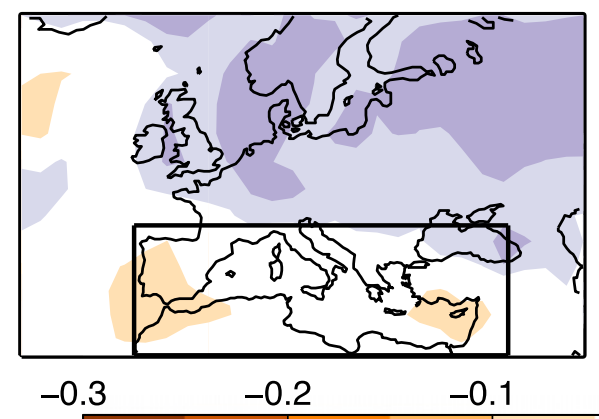

e) high tropical amp + weak vortex

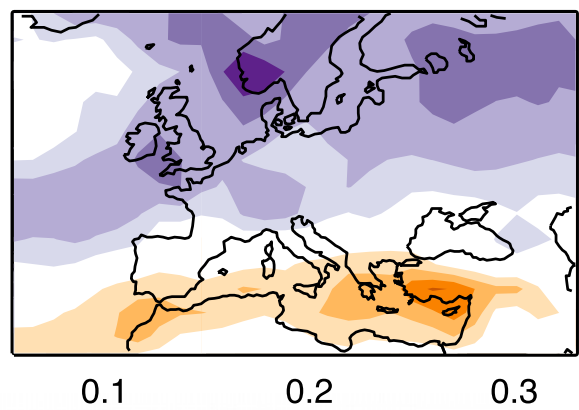

$\mathrm{mm} / \mathrm{day} / \mathrm{K}$

FIG. 8. As in Fig. 7, but for the cold season Mediterranean precipitation response per degree of global warming in (a),(b),(d),(e) the same four storylines and (c) the multimodel mean (mm day $\left.{ }^{-1} \mathrm{~K}^{-1}\right)$. The boxes in (b) and (d) delimit the area used to evaluate the regional precipitation change in Fig. 9.

North Atlantic storm-track behavior. Future projections of the North Atlantic storm track are characterized by low confidence but suggest a slight tendency toward an increase in the number of extratropical cyclones over the United Kingdom (Collins et al. 2013; Feser et al. 2015).

We here quantify windiness as the 95 th percentile of the daily mean wind speed at $850 \mathrm{hPa}$ (Wind95x). Only a subset of 26 models provide the data to evaluate this diagnostic (see Table 1). Of the three considered remote drivers, only the stratospheric vortex strength is significantly associated with the future response in central European windiness (see Figs. 10a-c). As previously shown, the stratospheric uncertainty is associated with the uncertainty in the NAO-like response of the jet in the North Atlantic region, and central European wind storms are known to strongly respond to this type of circulation anomaly (Pinto et al. 2009).

Only two storylines, depending on the stratospheric response, have thus been considered. For consistency, these storylines have also been selected to lie in the same $80 \%$ confidence region used for the Mediterranean precipitation analyses (see blue dots in Fig. 6). The regional climate responses can be evaluated as

$$
\begin{aligned}
\frac{\Delta C_{x}}{\Delta T} & =\hat{a}_{x} \pm \hat{d}_{x} t, \quad \text { and } \\
t & =\sqrt{\chi^{2}(0.8 ; 2)} \sim 1.8 .
\end{aligned}
$$

The Euro-Atlantic wind95x response in these two storylines is presented in Figs. 11a and 11c, while the 
a)

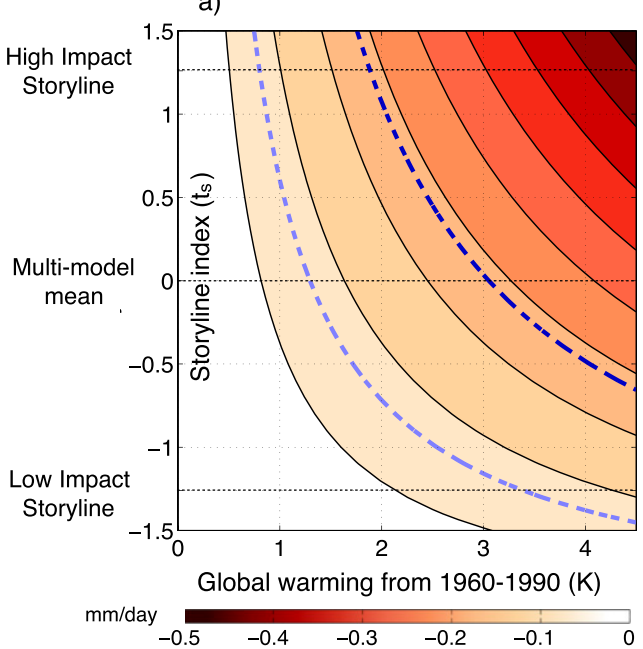

b)

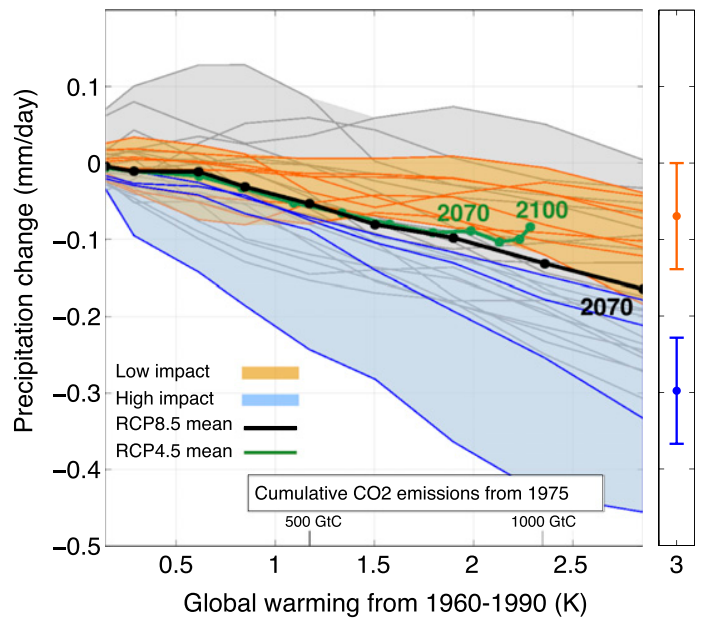

FIG. 9. Roles of global warming, storyline uncertainty, and emission scenario on Mediterranean precipitation change. (a) Best-estimate cold season area-averaged Mediterranean precipitation change according to the regression framework as a function of global warming and of the uncertainty in the storyline of atmospheric circulation change [see Eq. (6)]. The area average is computed within the box shown in Figs. 8b,d. The light blue dashed line shows the precipitation change associated with the time of emergence of the climate response as defined in Zappa et al. (2015a). The dark blue dashed line marks one standard deviation in the year-to-year variability. Both values are estimated using the average of the variability in the CMIP5 models. (b) Multimodel mean Mediterranean precipitation change in individual decades relative to the 1960-90 mean as a function of global warming under the RCP8.5 (black line) and RCP4.5 (green line) emission scenarios. Each dot represents a decadal mean value and some decades are indicated by the last year of the corresponding decade. The remaining lines show the individual model responses: blue for the models in the high-impact storyline, orange for the models in the low-impact storyline, and gray for the remaining models. The shading delimits the range of responses within each storyline. The individual model responses have been smoothed in time by two iterations of the 1-2-1 filter. Cumulative $\mathrm{CO}_{2}$ emissions are estimated according to the average transient climate response to cumulative carbon emissions as in Seneviratne et al. (2016). The small panel on the right indicates the $95 \%$ confidence intervals on the best-estimate response according to the regression framework in the high-impact (blue) and low-impact (orange) storylines for a 3-K global warming.

multimodel mean response is presented in Fig. 11b. Consistent with previous studies, a slight increase in central European windiness is found in the multimodel mean projection (Fig. 11b). However, the results from the storylines indicate that if the stratospheric vortex strengthens $\left(\sim 1 \mathrm{~m} \mathrm{~s}^{-1} \mathrm{~K}^{-1}\right)$, central European windiness is projected to more substantially increase, whereas if the stratospheric vortex weakens $\left(\sim-1.4 \mathrm{~m} \mathrm{~s}^{-1} \mathrm{~K}^{-1}\right)$ then European windiness remains largely unchanged. In the strong-vortex storyline, we estimate that a global warming relative to the $1960-90$ mean of about $1.8 \mathrm{~K}$ is required to exceed the time of emergence threshold $\left(\sim 0.5 \mathrm{~m} \mathrm{~s}^{-1}\right)$, while about $3.5 \mathrm{~K}$ of warming is needed to exceed the year-to-year variability threshold $\left(\sim 1 \mathrm{~m} \mathrm{~s}^{-1}\right)$, a) Polar amplification

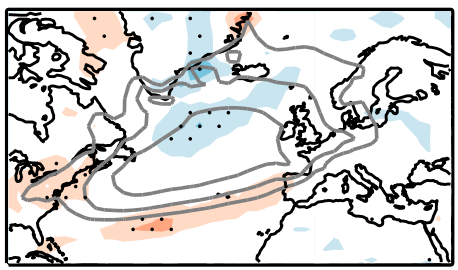

b) Tropical amplification

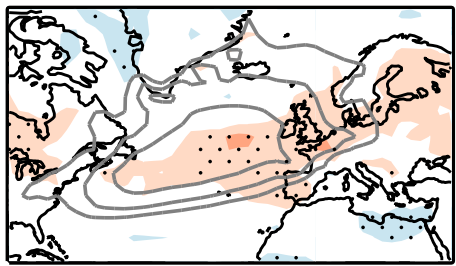

c) Stratospheric vortex

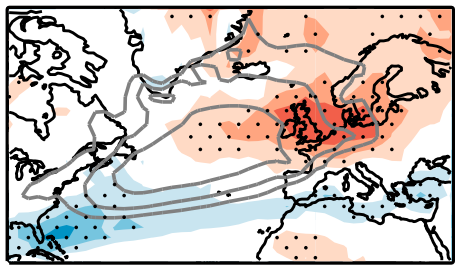

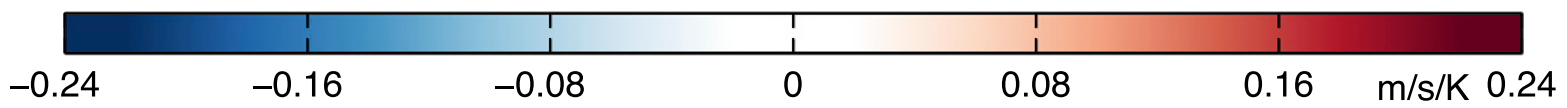

FIG. 10. As in Fig. 5, but for the sensitivity of the Euro-Atlantic windiness response associated with the uncertainty in the remote driver responses. Windiness is measured as the 95th percentile of the daily mean wind speed at $850 \mathrm{hPa}$ (wind95x). Gray contours mark the 20 (outermost), 22, and $24 \mathrm{~m} \mathrm{~s}^{-1}$ (innermost) wind95x values in the multimodel mean of the historical simulations. 
a) Weak vortex storyline

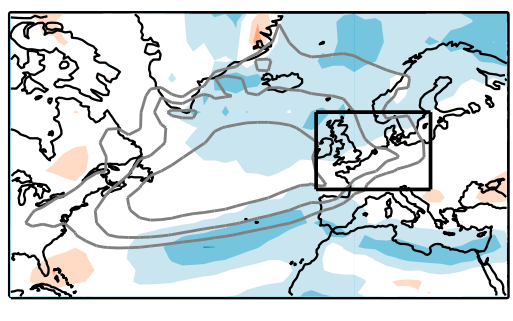

b) Multi-model mean

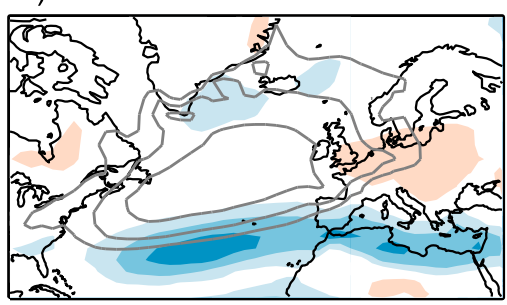

c) Strong vortex storyline

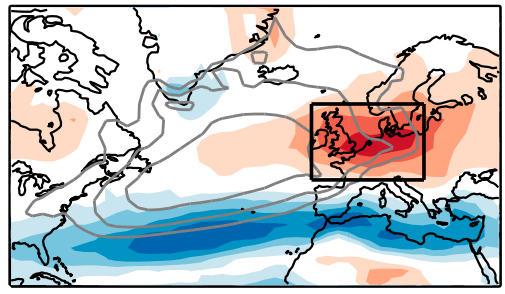

$0.4 \quad 0.6$ $\mathrm{m} / \mathrm{s} / \mathrm{K}$

FIG. 11. Euro-Atlantic windiness response per degree of global warming $\left(\mathrm{m} \mathrm{s}^{-1} \mathrm{~K}^{-1}\right)$ according to two plausible storylines of climate change that are conditioned on the stratospheric vortex response. The panels show the (a) weak vortex storyline, (b) multimodel mean, and (c) strong vortex storyline. The box defines the area used to compute the central European windiness change in Fig. 12.

respectively (Fig. 12a). In contrast, extreme global warming levels $(>4 \mathrm{~K})$ are required to reach both thresholds according to the multimodel mean. In the weak-vortex storyline an increase in central European windiness seems instead unlikely to happen.

These results are confirmed by grouping individual models according to their stratospheric vortex response. In particular, consistent with Eq. (7), models are grouped depending on whether the standardized anomaly in the scaled vortex response $\left(\Delta U_{\text {strat }} / \Delta T\right)$ is greater than 0.5 or smaller than -0.5 . Figure $12 \mathrm{~b}$ shows that none of the models following the weak-vortex storyline project an increase in central European windiness with global warming. In contrast, most of the models in the strong-vortex storyline show increased windiness over central Europe.

\section{Discussion}

\section{a. Emission scenarios and the pattern scaling assumption}

All these results are based on the pattern scaling assumption that, in each model, the amplitude of the climate response exclusively depends on the global warming signal and is not affected by the rate or duration of the $\mathrm{CO}_{2}$ emissions. To test this, Figs. $9 \mathrm{~b}$ and $12 \mathrm{~b}$ present the multimodel mean decadal precipitation and windiness responses under both the RCP4.5 and RCP8.5 scenarios. The dependency on the emission scenario is generally very small, except for Mediterranean precipitation in the last decades (2070-2100) of the RCP4.5 scenario (Fig. 9b). This is explained by the stabilization of $\mathrm{CO}_{2}$ concentrations at about $540 \mathrm{ppm}$ in $\mathrm{RCP} 4.5$ a)

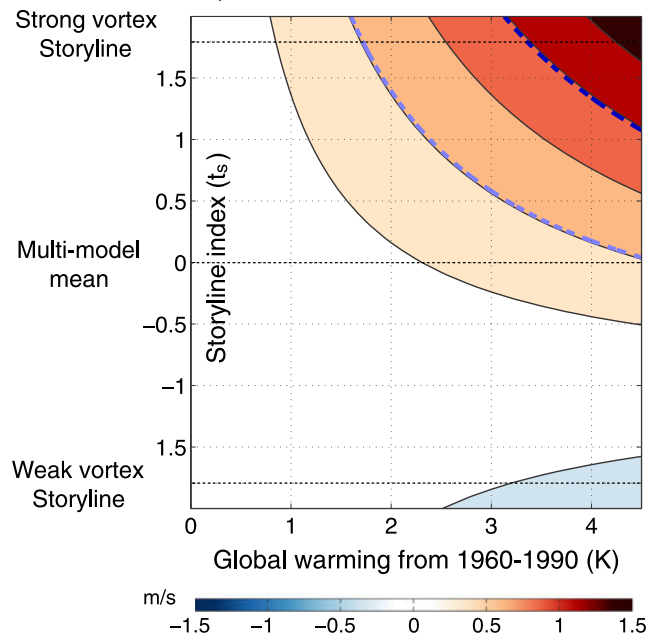

b)

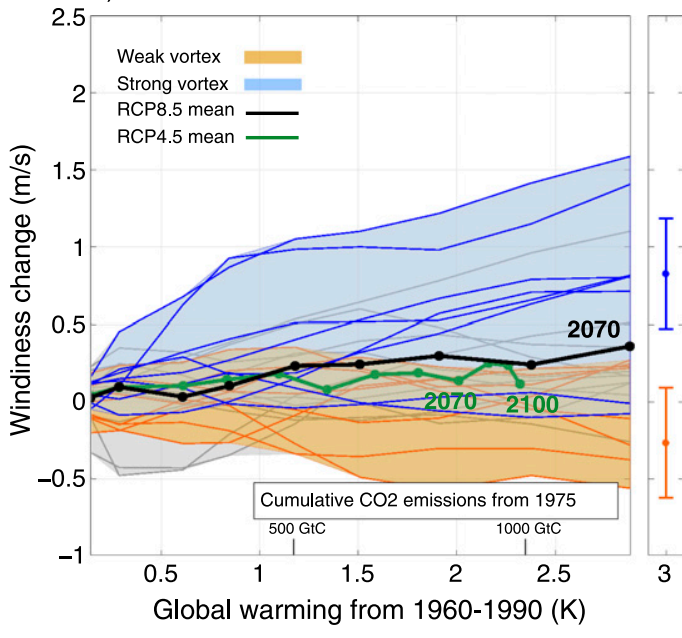

FIG. 12. As in Fig. 9, but for the change in Wind95x area averaged in central Europe. (a) The storyline index is the standardized anomaly in the stratospheric vortex response. The area average is computed within the box shown in Figs. 11a,c. (b) The blue lines and shading refer to the models in the strong vortex storyline, while orange lines and shading refer to the models in the weak vortex storyline. 

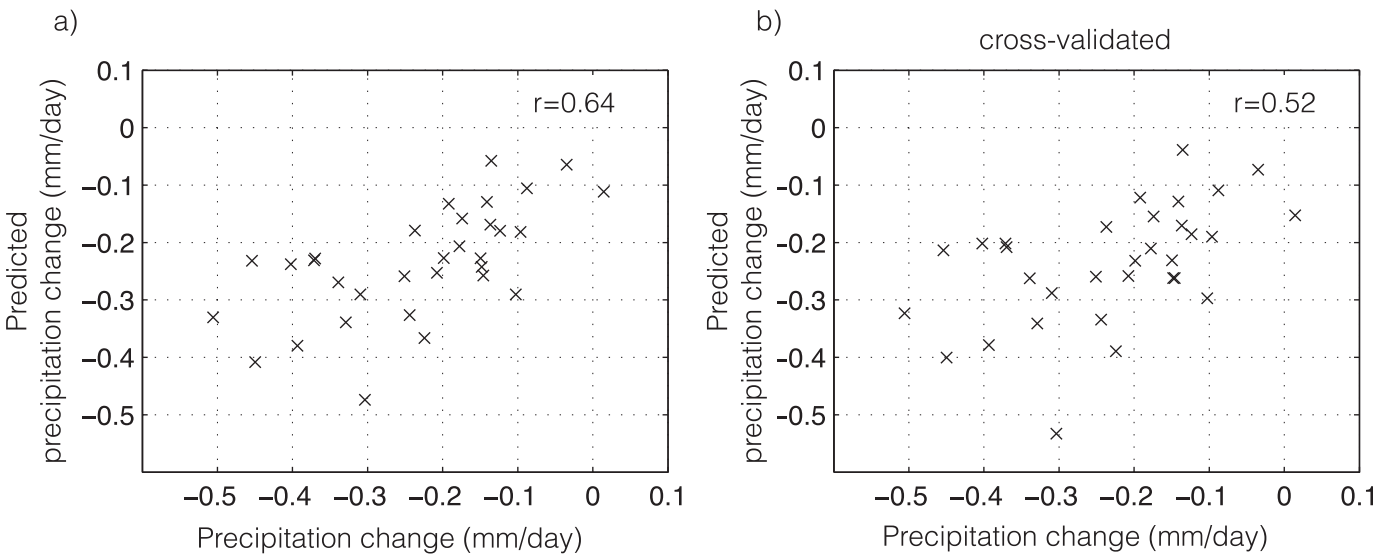

c)
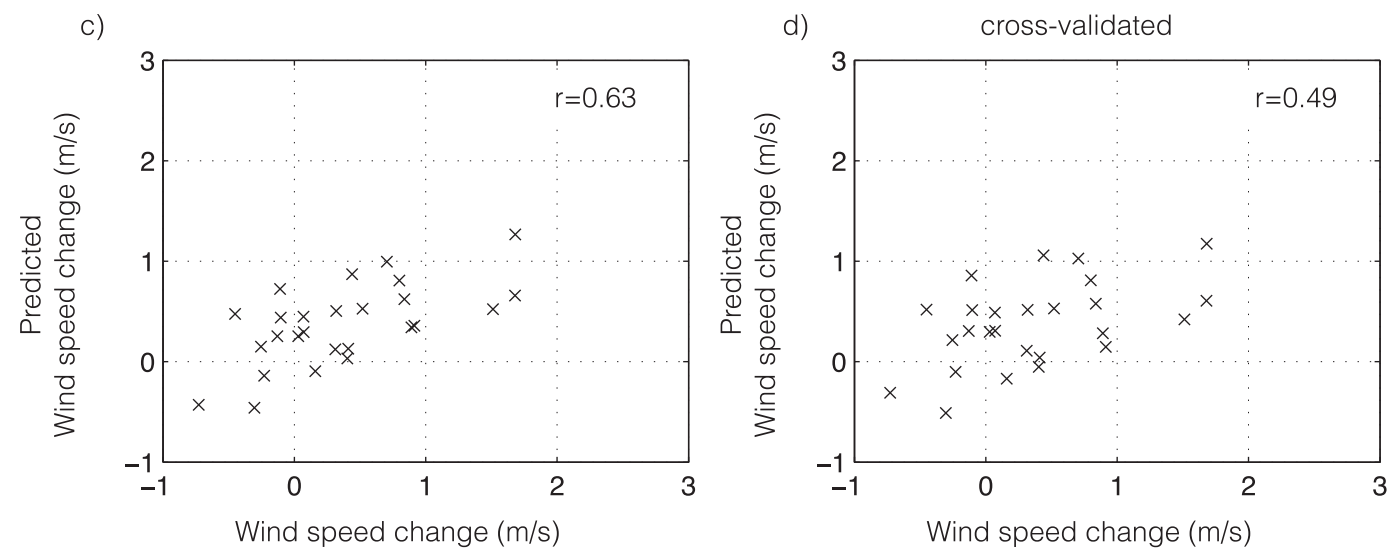

FIG. 13. (a) Scatterplot of the predicted Mediterranean precipitation change estimated from the regression framework against the actual precipitation change found in the individual models. (b) As in (a), but the predicted values ( $y$ axis) are estimated using the leave-one-out cross validation. (c),(d) As in (a),(b), but for the projected change in central European windiness.

(Thomson et al. 2011), which is absent in RCP8.5. Because of slow adjustments in the ocean, the stabilization can lead to changes in the pattern of the atmospheric circulation response (Mitchell 2003; Tebaldi and Arblaster 2014), and stabilized simulations should be used for any analysis of equilibrium climate impacts. Nonetheless, the impact of climate stabilization is small compared to the spread between the higher-impact and lower-impact storylines (Fig. 9b), which justifies the use of pattern scaling to interpret the uncertainty in the atmospheric circulation response.

\section{b. $1.5^{\circ}$ versus $2.0^{\circ} \mathrm{C}$ global warming}

Figures 9a and 12a can be used to compare the transient climate response at $1.5^{\circ}$ versus $2.0^{\circ} \mathrm{C}$ global warming on preindustrial levels against the uncertainty due to different plausible storylines of circulation change. After accounting for $0.3^{\circ} \mathrm{C}$ global warming from preindustrial to the 1960-90 mean employed here (Hartmann et al. 2013), we find that the change in Mediterranean precipitation in the multimodel mean from $1.5^{\circ}$ to $2^{\circ} \mathrm{C}$ warming is $-0.031 \pm$ $0.005 \mathrm{~mm} \mathrm{day}^{-1}$, while the difference between the highand low-impact storylines at $1.5^{\circ} \mathrm{C}$ warming is estimated as $0.09 \pm 0.04 \mathrm{~mm} \mathrm{day}^{-1}$. For the central European windiness, the impact from the additional $0.5^{\circ} \mathrm{C}$ of warming in the multimodel mean is $0.05 \pm 0.03 \mathrm{~m} \mathrm{~s}^{-1}$, while the difference between the two storylines is $0.4 \pm 0.2 \mathrm{~m} \mathrm{~s}^{-1}$. In both cases, the storyline uncertainty is several times larger than the estimated impact from the additional $0.5^{\circ} \mathrm{C}$ of warming from $1.5^{\circ}$ to $2^{\circ} \mathrm{C}$ using the multimodel mean.

\section{c. Cross validation}

The Pearson correlation coefficient between the areaaveraged Mediterranean precipitation response simulated by the individual models and predicted by the regression framework is 0.64 (Fig. 13a). A correlation of 0.63 is found for the central European windiness change (Fig. 13c). This shows that about $40 \%$ of the variance in the CMIP5 responses in these regional impact-relevant metrics can be linked to global aspects of climate 
change. The potential of the framework to predict these regional climate responses given the remote driver responses has been cross validated using the leave-one-out approach, in which the model whose response is being predicted is not used to train the regression framework. In this case, as expected, the correlation coefficient drops slightly, but we still observe a significant association between the predicted and model simulated regional precipitation and windiness responses (Figs. 13b,d). This confirms that projections of impact-relevant aspects of European climate change could be sharpened if the response of the remote drivers is understood.

\section{Summary and conclusions}

This paper has presented a novel storyline approach to better understand, characterize, and communicate the uncertainty in the atmospheric circulation response of the CMIP5 model future projections. Building on results from Manzini et al. (2014), it has been shown that different plausible storylines of atmospheric circulation change can be defined depending on the responses in three different remote drivers of climate: the tropical and polar amplification of global warming and changes in the stratospheric vortex strength. The pattern of the circulation change in each storyline depends on the relative responses of the drivers (Fig. 7), while the overall amplitude of the changes depends on global warming. The combined effect of the storyline and global warming uncertainty on the future projections can then be summarized using simple plots, as demonstrated in Fig. 9 for the cold season Mediterranean precipitation and in Fig. 12 for the cold season central European windiness.

The main findings of this work are the following:

- The impact of climate change on the cold season Mediterranean precipitation decline and on central European windiness might be better assessed once the responses of the tropical amplification and of the stratospheric vortex strength are better understood.

- A high-impact storyline for European climate change is found for a future strengthening of the stratospheric vortex and a high tropical amplification of global warming $\left(\sim 2 \mathrm{~K} \mathrm{~K}^{-1}\right)$. This storyline is characterized by a large reduction in the cold-season Mediterranean precipitation (locally up to $0.2 \mathrm{~mm}$ day $^{-1} \mathrm{~K}^{-1}$ of global warming). The strong vortex storyline is also characterized by a large increase in central European windiness (locally up to $0.4 \mathrm{~m} \mathrm{~s}^{-1} \mathrm{~K}^{-1}$ of global warming). In contrast, a weakening of the stratospheric vortex and a low tropical amplification of global warming imply a low-impact storyline of European climate change, which is characterized by considerably smaller circulation and precipitation changes.

- Using this approach, we do not find strong evidence that the uncertainty in polar amplification plays a dominant role for the future response of the two examined aspects of European climate. This does not exclude the possibility that polar amplification could still play a role for different climate aspects or in different seasonal averages. It is also possible that the sensitivity to polar amplification is obscured by the different model circulation biases, which can lead to inconsistent responses to polar amplification across the models.

- It is difficult to predict the benefit of limiting global warming at $1.5^{\circ}$ versus $2^{\circ} \mathrm{C}$ for Mediterranean precipitation and European windiness, as the magnitude of the benefit depends strongly on the storyline of circulation change. At $1.5^{\circ} \mathrm{C}$ warming over preindustrial levels, the impact of the storyline uncertainty in the Mediterranean precipitation response is about 3 times larger than the impact from an additional $0.5^{\circ} \mathrm{C}$ of warming. The impact of the storyline uncertainty is even larger for the European windiness response.

An advantage of the storyline approach is that it provides a simple way of characterizing the uncertainty in the climate change response, which can be particularly useful in the context of climate services. The storyline approach enables to highlight dependencies between different impact-relevant aspects of climate change, which can be important to evaluate climate risk at the continental scale. For example, we have shown that storylines characterized by a larger reduction in Mediterranean precipitation are also associated with a larger increase in both northern European precipitation (Fig. 8) and western European windiness (Fig. 11). These analyses can also be extended to describe the climate response in other impact-relevant aspects of climate change (e.g., soil moisture, annual maximum temperature, accumulated precipitation over 5 days, etc.). Comparing the different storylines would identify whether the projections of these aspects of climate change also depend on the atmospheric circulation, or whether they could be well constrained based on global warming only (e.g., Seneviratne et al. 2016). The necessity to assess future climate risks has also led to the development of $\mathrm{H}++$ scenarios (Wade et al. 2015). These describe worst case scenarios of regional climate impacts, which, despite being unlikely, cannot be ruled out according to current knowledge. These high-impact storylines provide guidance on such possible large responses in a self-consistent manner across different impact variables.

Storylines of atmospheric circulation change might also be valuable to identify the subset of CMIP5 GCMs 
that, given limited resources, should be selected to drive regional climate and impact models. Different studies have highlighted the importance of retaining the full range of possible GCM responses in these analyses (Kendon et al. 2010; McSweeney et al. 2015). However this can be difficult to achieve: McSweeney and Jones (2016) showed how the five CMIP5 models analyzed in the Intersectorial Impact Model Intercomparison Project (ISIMIP) (Warszawski et al. 2014) tend to on average capture about half of the CMIP5 spread in the precipitation projections across different regions. Selecting at least one model per storyline of atmospheric circulation change would incorporate a plausible range of atmospheric circulation responses, which is a necessary, although not sufficient, requirement to capture the spread in the regional precipitation and windiness responses.

Some of the processes that contribute to shape the response of the remote drivers are already known. Cloud radiative feedbacks tend to warm the tropics and, through changes in the moist lapse rate, contribute to the tropical amplification of global warming in the upper troposphere (Ceppi and Hartmann 2016). Arctic sea ice loss, the increased poleward moisture transport, and the structure of the Arctic boundary layer contribute to the polar amplification (Pithan and Mauritsen 2014). The stratospheric vortex responds to changes in the upward propagation and breaking of planetary waves. Sigmond and Scinocca (2010) suggest that the model biases in the climatological structure of the uppertropospheric jet might control the uncertainty in the vortex response to climate change. However, uncertainty in the stratospheric vortex response can also arise from forced changes in the surface boundary conditions. For example, regional changes in the Arctic sea ice (Sun et al. 2015; Gastineau et al. 2016) or in the Atlantic meridional overturning circulation (Omrani et al. 2014) have been shown to affect the strength of the stratospheric vortex in individual climate model experiments.

Converting this knowledge into a probabilistic assessment of the driver responses to climate change can improve the projections of midlatitude circulation change, but achieving this will be a major challenge. Nonetheless, useful information for regional impact assessment could also result from rejecting particular storylines. For example, the identified high-impact storylines of European climate change include a strengthening of the stratospheric vortex. Can this be considered a plausible response? If this could be shown to be unlikely, the projected risks associated with changing Mediterranean precipitation and central European windiness could be better bounded.
Acknowledgments. We acknowledge the World Climate Research Programme Working Group on Coupled Modelling, which is responsible for CMIP, and the modelling groups listed in Table 1 for producing the simulations and making available their output. CMIP data were obtained from the British Atmospheric Data Centre. We are also grateful for the constructive comments of three anonymous reviewers. This study is supported by the "Understanding the atmospheric circulation response to climate change" (ACRCC, ERC Advanced Grant 339390) project.

\section{REFERENCES}

Ambaum, M., B. J. Hoskins, and D. Stephenson, 2001: Arctic Oscillation or North Atlantic Oscillation? J. Climate, 14, 3495-3507, doi:10.1175/1520-0442(2001)014<3495:AOONAO>2.0.CO;2.

Bracegirdle, T. J., and D. B. Stephenson, 2013: On the robustness of emergent constraints used in multimodel climate change projections of Arctic warming. J. Climate, 26, 669-678, doi:10.1175/ JCLI-D-12-00537.1.

Butler, A. H., D. W. J. Thompson, and R. Heikes, 2010: The steadystate atmospheric circulation response to climate change-like thermal forcings in a simple general circulation model. J. Climate, 23, 3474-3496, doi:10.1175/2010JCLI3228.1.

Caldwell, P. M., C. S. Bretherton, M. D. Zelinka, S. A. Klein, B. D. Santer, and B. M. Sanderson, 2014: Statistical significance of climate sensitivity predictors obtained by data mining. Geophys. Res. Lett., 41, 1803-1808, doi:10.1002/2014GL059205.

Ceppi, P., and D. L. Hartmann, 2016: Clouds and the atmospheric circulation response to warming. J. Climate, 29, 783-799, doi:10.1175/JCLI-D-15-0394.1.

Chadwick, R., I. Boutle, and G. Martin, 2013: Spatial patterns of precipitation change in CMIP5: Why the rich do not get richer in the tropics. J. Climate, 26, 3803-3822, doi:10.1175/JCLI-D-12-00543.1.

Collins, M., and Coauthors, 2013: Long-term climate change: Projections, commitments and irreversibility. Climate Change 2013: The Physical Science Basis, T. F. Stocker et al., Eds., Cambridge University Press, 1029-1136.

Della-Marta, P. M., and J. G. Pinto, 2009: Statistical uncertainty of changes in winter storms over the North Atlantic and Europe in an ensemble of transient climate simulations. Geophys. Res. Lett., 36, L14703, doi:10.1029/2009GL038557.

Deser, C., L. Sun, R. A. Tomas, and J. Screen, 2016: Does ocean coupling matter for the northern extratropical response to projected Arctic sea ice loss? Geophys. Res. Lett., 43, 21492157, doi:10.1002/2016GL067792.

Feser, F., M. Barcikowska, O. Krueger, F. Schenk, R. Weisse, and L. Xia, 2015: Storminess over the North Atlantic and northwestern Europe-A review. Quart. J. Roy. Meteor. Soc., 141, 350-382, doi:10.1002/qj.2364.

Gastineau, G., B. L'Hévéder, F. Codron, and C. Frankignoul, 2016: Mechanisms determining the winter atmospheric response to the Atlantic overturning circulation. J. Climate, 29, 3767-3785, doi:10.1175/JCLI-D-15-0326.1.

Giorgi, F., C. Jones, and G. R. Asrar, 2009: Addressing climate information needs at the regional level: The CORDEX framework. WMO Bull., 58, 175-183.

Hall, A., and X. Qu, 2006: Using the current seasonal cycle to constrain snow albedo feedback in future climate change. Geophys. Res. Lett., 33, L03502, doi:10.1029/2005GL025127. 
Hartmann, D. L., and Coauthors, 2013: Observations: Atmosphere and surface. Climate Change 2013: The Physical Science Basis, T. F. Stocker et al., Eds., Cambridge University Press, 159-254.

Harvey, B. J., L. C. Shaffrey, and T. J. Woollings, 2014: Equator-topole temperature differences and the extra-tropical storm track responses of the CMIP5 climate models. Climate Dyn., 43, 1171-1182, doi:10.1007/s00382-013-1883-9.

Hawkins, E., and R. Sutton, 2012: Time of emergence of climate signals. Geophys. Res. Lett., 39, L01702, doi:10.1029/2011GL050087.

Hazeleger, W., B. J. J. M. van den Hurk, E. Min, G. J. van Oldenborgh, A. C. Petersen, D. A. Stainforth, E. Vasileiadou, and L. A. Smith, 2015: Tales of future weather. Nat. Climate Change, 5, 107-113, doi:10.1038/nclimate2450.

Hitchcock, P., and I. R. Simpson, 2014: The downward influence of stratospheric sudden warmings. J. Atmos. Sci., 71, 3856-3876, doi:10.1175/JAS-D-14-0012.1.

Hoerling, M., J. Eischeid, J. Perlwitz, X. Quan, T. Zhang, and P. Pegion, 2012: On the increased frequency of Mediterranean drought. J. Climate, 25, 2146-2161, doi:10.1175/ JCLI-D-11-00296.1.

Hulme, M., 2016: $1.5^{\circ} \mathrm{C}$ and climate research after the Paris Agreement. Nat. Climate Change, 6, 222-224, doi:10.1038/ nclimate2939.

Kelley, C. P., S. Mohtadi, M. A. Cane, R. Seager, and Y. Kushnir, 2015: Climate change in the Fertile Crescent and implications of the recent Syrian drought. Proc. Natl. Acad. Sci. USA, 112, 3241-3246, doi:10.1073/pnas.1421533112.

Kendon, E. J., R. G. Jones, E. Kjellström, and J. M. Murphy, 2010: Using and designing GCM-RCM ensemble regional climate projections. J. Climate, 23, 6485-6503, doi:10.1175/ 2010JCLI3502.1.

Knutti, R., R. Furrer, C. Tebaldi, J. Cermak, and G. A. Meehl, 2010: Challenges in combining projections from multiple climate models. J. Climate, 23, 2739-2758, doi:10.1175/2009JCLI3361.1.

_, D. Masson, and A. Gettelman, 2013: Climate model genealogy: Generation CMIP5 and how we got there. Geophys. Res. Lett., 40, 1194-1199, doi:10.1002/grl.50256.

Lenderink, G., B. van den Hurk, A. Klein Tank, G. J. van Oldenborgh, E. van Meijgaard, H. de Vries, and J. J. Beersma, 2014: Preparing local climate change scenarios for the Netherlands using resampling of climate model output. Environ. Res. Lett., 9, 115008, doi:10.1088/1748-9326/9/11/115008.

Ma, J., and S.-P. Xie, 2013: Regional patterns of sea surface temperature change: A source of uncertainty in future projections of precipitation and atmospheric circulation. J. Climate, 26, 2482-2501, doi:10.1175/JCLI-D-12-00283.1.

Manzini, E., and Coauthors, 2014: Northern winter climate change: Assessment of uncertainty in CMIP5 projections related to stratosphere-troposphere coupling. J. Geophys. Res. Atmos., 119, 7979-7998, doi:10.1002/2013JD021403.

McSweeney, C. F., and R. G. Jones, 2016: How representative is the spread of climate projections from the 5 CMIP5 GCMs used in ISI-MIP? Climate Serv., 1, 24-29, doi:10.1016/j.cliser.2016.02.001.

,,-- R. W. Lee, and D. P. Rowell, 2015: Selecting CMIP5 GCMs for downscaling over multiple regions. Climate Dyn., 44, 3237-3260, doi:10.1007/s00382-014-2418-8.

Meredith, E. P., V. A. Semenov, D. Maraun, W. Park, and A. V. Chernokulsky, 2015: Crucial role of Black Sea warming in amplifying the 2012 Krymsk precipitation extreme. Nat. Geosci., 8, 615-619, doi:10.1038/ngeo2483.

Mitchell, T. D., 2003: Pattern scaling: An examination of the accuracy of the technique for describing future climates. Climatic Change, 60, 217-242, doi:10.1023/A:1026035305597.
Omrani, N. E., N. S. Keenlyside, J. Bader, and E. Manzini, 2014: Stratosphere key for wintertime atmospheric response to warm Atlantic decadal conditions. Climate Dyn., 42, 649-663, doi:10.1007/s00382-013-1860-3.

Pierce, D. W., T. P. Barnett, B. D. Santer, and P. J. Gleckler, 2009: Selecting global climate models for regional climate change studies. Proc. Natl. Acad. Sci. USA, 106, 8441-8446, doi:10.1073/ pnas.0900094106.

Pinto, J. G., S. Zacharias, A. Fink, G. C. Leckebusch, and U. Ulbrich, 2009: Factors contributing to the development of extreme North Atlantic cyclones and their relationship with the NAO. Climate Dyn., 32, 711-737, doi:10.1007/ s00382-008-0396-4.

Pithan, F., and T. Mauritsen, 2014: Arctic amplification dominated by temperature feedbacks in contemporary climate models. Nat. Geosci., 7, 181-184, doi:10.1038/ngeo2071.

Scaife, A., and Coauthors, 2014: Skillful long-range prediction of European and North American winters. Geophys. Res. Lett., 41, 2514-2519, doi:10.1002/2014GL059637.

Schwierz, C., P. Köllner-Heck, E. Zenklusen Mutter, D. N. Bresch, P. L. Vidale, M. Wild, and C. Schär, 2010: Modelling European winter wind storm losses in current and future climate. Climatic Change, 101, 485-514, doi:10.1007/s10584-009-9712-1.

Seager, R., H. Liu, N. Henderson, I. Simpson, C. Kelley, T. Shaw, Y. Kushnir, and M. Ting, 2014: Causes of increasing aridification of the Mediterranean region in response to rising greenhouse gases. J. Climate, 27, 4655-4676, doi:10.1175/ JCLI-D-13-00446.1.

Seneviratne, S. I., M. G. Donat, A. J. Pitman, R. Knutti, and R. L. Wilby, 2016: Allowable $\mathrm{CO}_{2}$ emissions based on regional and impact-related climate targets. Nature, 529, 477-483, doi:10.1038/nature16542.

Shepherd, T. G., 2014: Atmospheric circulation as a source of uncertainty in climate change projections. Nat. Geosci., 7, 703708, doi:10.1038/ngeo2253.

_ _ 2016a: A common framework for approaches to extreme event attribution. Curr. Climate Change Rep., 2, 28-38, doi:10.1007/s40641-016-0033-y.

_ 2016b: Effects of a warming Arctic. Science, 353, 989-990, doi:10.1126/science.aag2349.

Sigmond, M., and J. F. Scinocca, 2010: The influence of the basic state on the Northern Hemisphere circulation response to climate change. J. Climate, 23, 1434-1446, doi:10.1175/ 2009JCLI3167.1.

Simpson, I. R., R. Seager, M. Ting, and T. A. Shaw, 2016: Causes of change in Northern Hemisphere winter meridional winds and regional hydroclimate. Nat. Climate Change, 6, 65-70, doi:10.1038/nclimate2783.

Stroeve, J. C., V. Kattsov, A. Barrett, M. Serreze, T. Pavlova, M. Holland, and W. N. Meier, 2012: Trends in Arctic sea ice extent from CMIP5, CMIP3 and observations. Geophys. Res. Lett., 39, L16502, doi:10.1029/2012GL052676.

Sun, L., C. Deser, and R. A. Tomas, 2015: Mechanisms of stratospheric and tropospheric circulation response to projected Arctic sea ice loss. J. Climate, 28, 7824-7845, doi:10.1175/ JCLI-D-15-0169.1.

Swiss Re, 2010: Natural catastrophes and man-made disasters in 2009: Catastrophes claim fewer victims, insured losses fall [Available online at http://institute.swissre.com/research/ overview/sigma/1_2010.html.]

Taylor, K., R. Stouffer, and G. Meehl, 2012: An overview of CMIP5 and the experiment design. Bull. Amer. Meteor. Soc., 93, 485498, doi:10.1175/BAMS-D-11-00094.1. 
Tebaldi, C., and J. M. Arblaster, 2014: Pattern scaling: Its strengths and limitations, and an update on the latest model simulations. Climatic Change, 122, 459-471, doi:10.1007/s10584-013-1032-9.

Thomson, A. M., and Coauthors, 2011: RCP4.5: A pathway for stabilization of radiative forcing by 2100 . Climatic Change, 109, 77-94, doi:10.1007/s10584-011-0151-4.

van den Hurk, B., P. Siegmund, and A. Klein Tank, Eds., 2014a: KNMI'14: Climate change scenarios for the 21st century-A Netherlands perspective. KNMI Tech. Rep. WR 2014-01, 120 pp. , G. J. van Oldenborgh, G. Lenderink, W. Hazeleger, R. Haarsma, and H. de Vries, 2014b: Drivers of mean climate change around the Netherlands derived from CMIP5. Climate Dyn., 42, 1683-1697, doi:10.1007/s00382-013-1707-y.

Vihma, T., 2014: Effects of Arctic sea ice decline on weather and climate: A review. Surv. Geophys., 35, 1175-1214, doi:10.1007/ s10712-014-9284-0.

Wade, S., and Coauthors, 2015: Developing $\mathrm{H}++$ climate change scenarios for heat waves, droughts, floods, windstorms and cold snaps. Committee on Climate Change Tech. Rep., 145 pp.

Warszawski, L., K. Frieler, V. Huber, F. Piontek, O. Serdeczny, and J. Schewe, 2014: The Inter-Sectoral Impact Model
Intercomparison Project (ISI-MIP): Project framework. Proc. Natl. Acad. Sci. USA, 111, 3228-3232, doi:10.1073/ pnas. 1312330110.

Woollings, T., 2010: Dynamical influences on European climate: An uncertain future. Philos. Trans. Roy. Soc., 368A, 37333756, doi:10.1098/rsta.2010.0040.

—, J. M. Gregory, J. G. Pinto, M. Reyers, and D. J. Brayshaw, 2012: Response of the North Atlantic storm track to climate change shaped by ocean-atmosphere coupling. Nat. Geosci., 5, 313-317, doi:10.1038/ngeo1438.

Zappa, G., L. C. Shaffrey, and K. I. Hodges, 2013: The ability of CMIP5 models to simulate North Atlantic extratropical cyclones. J. Climate, 26, 5379-5396, doi:10.1175/ JCLI-D-12-00501.1.

, B. J. Hoskins, and T. G. Shepherd, 2015a: Improving climate change detection through optimal seasonal averaging: The case of the North Atlantic jet and European precipitation. J. Climate, 28, 6381-6397, doi:10.1175/JCLI-D-14-00823.1.

, — , and - 2015b: The dependence of wintertime Mediterranean precipitation on the atmospheric circulation response to climate change. Environ. Res. Lett., 10, 104012, doi:10.1088/1748-9326/10/10/104012. 